\title{
Application-oriented Outstanding Engineers Training Based on Regional Economy
}

\author{
Sheng-Gui CHEN ${ }^{1, a,{ }^{*}, \text { Shou-Yan ZHONG }}{ }^{1, b}$, Zhen-Zhong SUN ${ }^{1, c}$, Nan LI ${ }^{1, d}$ \\ ${ }^{1}$ School of Mechanical Engineering, Dongguan University of Technology, Dongguan, 523808, P. R. \\ China \\ asegi-11@163.com, ’bzhongy@263.net, csunzhzh@tom.com, ddglglinan@163.com \\ ${ }^{*}$ Corresponding Author
}

Keywords: Application-oriented, Outstanding engineer, “3+1”Mode, Regional Economic.

\begin{abstract}
Actively in response to and participating in the Education Ministry's deployment of "Plan for Educating and Training Outstanding Engineers (PETOE)", we are take Mechanical Design, Manufacturing and Its Automation specialty as the first batch of pilot. In this paper, with the " $3+1$ " mode, we re-adjust the theoretical teaching system and the practice teaching, so as to strengthen the enterprise engineering practice; in an effort to improve the students' engineering awareness, qualities and practical abilities; and cultivate the application-oriented outstanding engineers, who has high innovation and can meet the needs of Dongguan regional economic development.
\end{abstract}

\section{Introduction}

"Plan for Educating and Training Outstanding Engineers (PETOE)" is an important measure, which adapt to our country new industrialization development needs and taking example by the successful experience of higher engineering education of developed countries in the world so as to create a engineering teaching mode with Chinese characteristics. It is very necessary to effectively solve the main problem of engineer training in our country and create a new situation of higher engineering education. It is a rare historical opportunity for development and a rare innovation platform for local application oriented colleges. Actively our school responses to participate in the Education Ministry's deployment of PETOE in 2010, our school has decided to take Mechanical Design, Manufacturing and Its Automation specialty as the first batch of pilot. The pilot specialty use " $3+1$ "mode, which means the students study at school for 3 years before they graduate, and they would have their professional internships and graduation design in the fourth school year. And it also means we re-adjust the theoretical teaching system and the practical teaching, so as to strengthen the enterprise engineering practice ability; in an effort to improve the students' engineering awareness, qualities and practical abilities; and cultivate the application-oriented outstanding engineers, who has high innovation and can meet the needs of Dongguan regional economic development.

\section{The cultivate condition of outstanding engineers}

\section{Outstanding faculty and teaching resources.}

Since our school has promoted from technical college to the undergraduate school in march 2002, the faculty of mechanical engineering specialty has expanded gradually, all the new teachers were graduated from outstanding university at home and aboard. we have a provincial Chinese-Swiss precision manufacturing technology center, a municipal digital design and manufacturing key laboratory, a field grade modern manufacturing engineering research center, two university level internship Experimental Demonstration Center, ten relatively stable practice bases in the provincial manufacturing enterprises. Approved by the ministry of education, Mechanical Design, Manufacturing and Its Automation specialty is the characteristic professional construction point of our school; we are carrying through talents training mode reform of Mechanical Design, Manufacturing and Its Automation specialty according to the Education Ministry's PETOE. 


\section{The basics of good cooperation between production and research projects.}

Mechanical engineering department has built close cooperation relationship with Dongguan XinYi group, Dongguan WeiYiDa group and Dongguan electrical and mechanical association, and we have supplied a large number of outstanding graduates for the local machinery industry. Aiming at the Pearl River and Dongguan mold industry, our school joined "CAE mold universities industry-university Alliance Program", which involved by many manufacturing enterprises, and we strengthen our school's communication with enterprises through CAE mold industry and university Alliance.

\section{The requirement of high-quality application-oriented talent.}

Dongguan machinery manufacturing enterprises are facing dual pressures of industrial and technological upgrading, at this point, high-quality applied talent will be the main requirement. With Dongguan local industry characteristics, and our extensive contacts with local business and with the convenience that most students of our school are from Dongguan and employment in Dongguan, our school cultivates applied and creative talents of college mechanical engineering specialty. It will greatly meet the need of Dongguan local machinery manufacturing industry to high-quality applied talent.

\section{Build Dongguan regional Enterprise, Academy and Research Alliance.}

Dongguan manufacturing industry (especially equipment manufacturing industry) is lack of technological talents. Therefore, many enterprises request that the university students should have longer internship in the enterprises, so as to let the students to know more about the enterprise and identify its enterprise culture and students can be familiar with enterprise production and engineering environment earlier. It is a good way for the enterprise to employ suitable engineer with technical talents, and it also does good to shorten the time of university graduates to adapt to work. With the basics of good cooperation between production and research projects and "CAE mold industry-university Alliance Program", we have strengthen extensive contacts with local business and built an industry-university Alliance which face to Dongguan regional Economical development in order to adjust to the PETOE of the education ministry, as is shown in Figure 1. We select some advantaged enterprises to establish engineering practice center in industry-university Alliance, so as to build a practices platform for the training of applied outstanding engineers.

\section{The " $3+1$ " training mode of outstanding engineer}

The PETOE of Mechanical Design, Manufacturing and Its Automation specialty use the training mode which the school and enterprise train together the students and it divide outstanding engineer training into two stages, including school learning and enterprise learning. Carrying out the " $3+1$ " training mode, means the students study at school for 3 years before they graduate, and they would have their professional internships and graduation design in the fourth school year. When we were making the "3+1" training mode of Mechanical Design, Manufacturing and Its Automation specialty, we first set education concept of "big project" and established the new concept of personnel training of "Advocating practice and return to engineering"; also, we made clear our training objective of Mechanical Design, Manufacturing and Its Automation specialty's main line is ability, it based on machinery industry and rely on Dongguan regional Enterprise, Academy and Research Alliance to make an effort to improve the students' engineering awareness, qualities and practical abilities; and cultivate the application-oriented outstanding engineers, who has high innovation and can meet the needs of Dongguan regional economic development. 


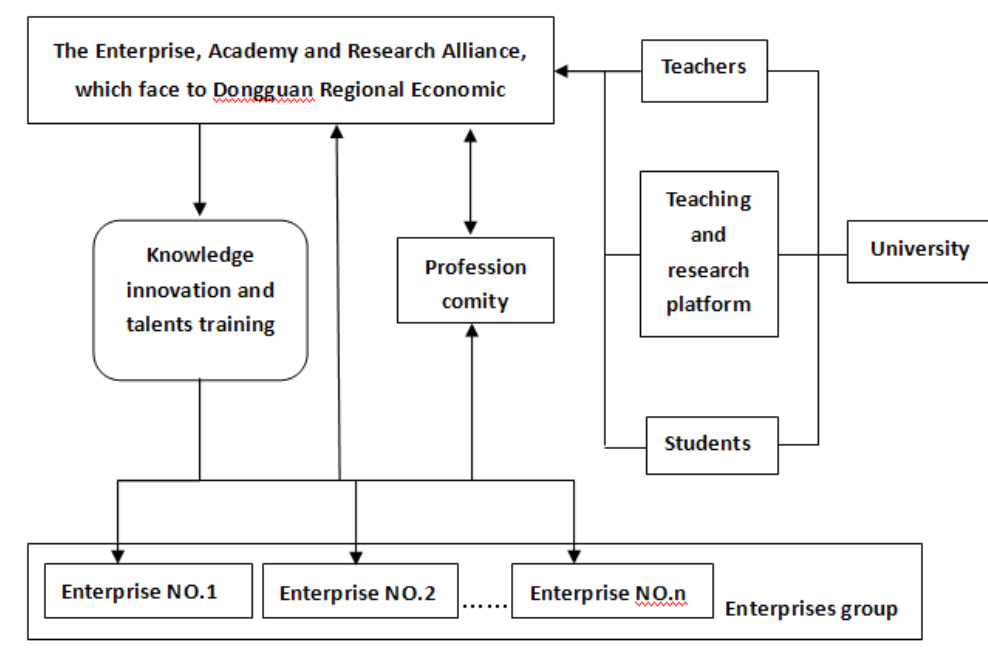

Figure 1. The Enterprise, Academy and Research Alliance, which face to Dongguan Regional Economic

In accordance with the school's engineering talents training requirements of "strong engineering ability; quickly work adjustment; high comprehensive quality", we have made comprehensive revision to the educational Direction, teaching plan, course outline, experimental outline, course outline design, graduate design outline of Mechanical Design, Manufacturing and Its Automation specialty. The new teaching plan has made earnest revision according to discipline training target and construction idea, and it forms new training plan and has the following characteristics:

A. Using " $3+1$ " training mode to the specialty to make restructuring and optimizing the whole, and closely integrated with the local manufacturing in Dongguan, we have thought fully of students' employment, practice environment, the local requirement to high quality application-orient talent and discipline's enterprise, academy and research cooperation in the future.

B. Focusing on Project-oriented, we are making application-oriented talent training target teaching plan and teaching outline of Mechanical Design, Manufacturing and Its Automation specialty ,which adapt to higher engineering education, local Machinery industry and the development of the equipment manufacturing industry.

C. The course teaching link of engineering teaching mode. Students of this specialty should master much humanistic, science and engineering knowledge; in the meantime, attention should be made to cultivate students' ability of finding and solving engineering problem, their system thinking, creative thinking and engineering innovation capacity by the course setting teaching carrier of project research.

D. The engineering innovation practice link. It emphasizes on taking engineering quality as the foundation and using engineer practice to deepen theory knowledge, so as to cultivate students' engineering innovation and technical practice ability.

E. The new plan face to Dongguan local manufacturing industry, it combine enterprise, academy and research and pay attention to learn from doing in order to balance theory and practice. With emphasis on local manufacturing product to realize whole process operation ability training. Also, it improve students' adapt ability and employment Competence through strengthening the cooperation between school and enterprise ability training.

F. Carrying out a series of college students' extracurricular quality expanding education, including innovation ability training plan, quality development plan, electrical and mechanical design and innovation competition, CAD/CAM students' innovation community and building college student innovation base; and fully introducing and using high-quality school resources at home and abroad to improve the teaching effect.

\section{The enterprise engineer practice of " $3+1$ " mode}

One year's enterprise training effort is the key to determine the success of PETOE. It reply on the Dongguan Regional Enterprise, Academy and Research Alliance, based on practical engineering background to give student their engineer basic training and cultivate them to have strong sense of social 
responsibility, good work ethic and the consciousness of good quality, environment, safety and service by the training of the enterprises' engineer practice enter. Knowing modern enterprise working process and culture help to comprehensively use mechanical engineering theory method and the technical means to analyze and solve practical engineering problems and participate in the production and operation of the system design, also, have operation and maintenance ability. Besides, it does good to cultivate students' strong sense of innovation consciousness and the preliminary ability of product development and design, technical reform and innovation. Knowing technical standard of mechanical engineering field and the related industry's policies, laws and regulations can help to have good management ability, strong communication ability, and team cooperation ability and have strong ability to adapt to the environment, which help to achieve the basic requirement of the mechanical engineer ability.

(1). We are going to use training modes of "Job Sharing" and "Project Scheme" to cultivate the students, when students study in the enterprise. Job sharing means students will have more post in rotation training so that they can complete the training of production processing, equipment maintenance and production organization, when aiming at enterprises' production link. Project Scheme means students will have mechanical products, mechanical equipment, electrical system design and process training by participating in project design and development of the enterprise.

(2). During students study in the enterprise, they will be treated like the enterprise's staff to accept the management of the enterprise; they will have "double system", which means the "school instructors" and "enterprise tutors" guide students together. The "school instructors", who is an engineering experienced teachers, is appointed by the college, they will give follow-up guidance to the students, who study in the enterprise; and the "enterprise tutors" are those engineering and technical personnel or management who is to engage in the corresponding titles and have rich theory and practice experiences, they will be responsible for students' learning in the enterprise and graduate design guidance as well as the management of the students.

(3). After the students practice in the enterprise for a year, they will make their graduate designs by themselves. They will reach the Post skill requirement of enterprise mechanical engineer after they have level trainings for a year, as is shown in Figure 2.

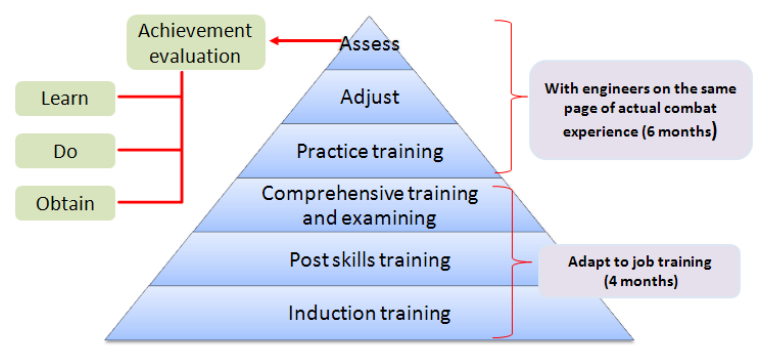

Figure 2. Enterprise engineering practice training mode

In the post skill training link, the enterprises will make different skill training for students according to different requirements of different posts; mainly they will use the form of "Job Sharing" to train students, including company standard, professional knowledge and professional skill training and so on. Students will know more about the departments of the company and the relevant departments' system operation; also, they can be familiar with the use of all kinds of engineering documents and to master relevant post skills.

In the link of comprehensive training and project practice, mainly we will use the form of "Project Scheme" to train students so as to let the students to achieve the work requirements of mechanical engineer. Project practice will be carried out with " $1+2+3$ " form, which means a project manager and 2 engineers will lead 3 interns to have repetitive design innovation design and assist to the technology research and development of enterprise project. Through project practice, students will be cultivated their professional ethics, engineering quality, engineering practice ability, innovation ability, team cooperation ability, hard-working spirit and social adaptation ability and so on. At the same time, it also offer convenience to ease engineering technical personnel shortages and help to reserve outstanding talents for the enterprises. 


\section{Summary}

The " $3+1$ " mode adopt the training of school-enterprises, it's the personnel training mode that major in facing the Dongguan economy and strengthening the engineering practice. The shortages of traditional engineering personnel training is that, the education divorced from industry and the theory divorced from practice. Implementing the " $3+1$ " outstanding engineer training project is trying to solve these problems. Compared with the traditional mode, reforming the Mechanical specialty personnel training mode, in order to achieve the organic unity of theory education and practice education, school studying and enterprises training. And develop the students' knowledge, ability and quality, consequently adapt to the outstanding engineer needs of new-type industrialization and innovative country development. For Dongguan regional economy, the " $3+1$ " training mode carrying out in the Mechanical Design Manufacturing and Automation Department, based on the engineering technology, try to improve the students' engineering awareness, quality and practice ability, train the innovative outstanding engineer adapt to the development of Dongguan economy. It's important and meaningful for accelerating the engineering education reform and improving the personnel training quality of our school.

\section{Acknowledgement}

The presented results are part of the project funded by the characteristic major construction of Guangdong higher institution "Mechanical Design, Manufacturing and Its Automation" (Project number: 263); teaching reform project of Guangdong higher education "The reform and practice of application-oriented personnel training mode of Mechanical Design, Manufacturing and Its Automation specialty, which based on the concept of CDIO" (Project number: BKYB2011081); the training project of Guangdong higher education teaching achievement award "The research and practice of mechanical engineering students' engineering ability training mode, which face to the Regional Economic Alliance" (Project number: 333); special item of the universities discipline construction of Guangdong Province and the quality of teaching and teaching reform project "Engineering practical education center of Mechanical Design, Manufacturing and Its Automation specialty" (Project number: XE120306); substantial projects of educational reform of Dongguan university of technology "The talents training program based on the CDIO mode and the research and practice of curriculum system reform of the Mechanical Design, Manufacturing and Its Automation" (Project number: E1206108 ).

\section{References}

[1] Weiwei Z 2010 Ministry of Education to start the implementation of "Plan for Educating and Training Outstanding Engineers" China. J. Education and vacation. 19: 20.

[2] Ke G 2010 The Idea and Exploration of Outstanding Engineer Training China. J. China University Teaching. 8: 4.

[3] Zhipan Y and Peihua J 2007 A Review of Studies on Practice Teaching of Engineering Education in China. China. J. Research in Higher Education of Engineering. 4: 74.

[4] Maoyuan P 2007 My opinion about application-oriented undergraduate colleges' orientation China. J. Exploring Education Development. 13: 4.

[5] Yongan G 2010 The discussion about the formulation of the teaching quality standard basis and requirements of application-oriented undergraduate colleges China. J. China University Teaching. 6: 12.

[6] Xiaohu C, Zhongjiang W and Jianqi L 2010 The characteristics and the development thinking of new application-oriented undergraduate colleges China. J. China University Teaching. 6: 4. 